\title{
AUTEKOLOGI BEGONIA DI SEBAGIAN KAWASAN TAMAN NASIONAL GUNUNG MERAPI
}

\section{AUTECOLOGY OF BEGONIA IN PART OF MOUNT MERAPI NATIONAL PARK}

\author{
NKE. UNDAHARTA DAN SUTOMO \\ Balai Konservasi Tumbuhan Kebun Raya "Eka Karya" Bali-LIPI \\ Candikuning, Baturiti, Tabanan, Bali 82191 \\ "e-mail : rosiundaharta@gmail.com
}

\section{INTISARI}

Penelitian dilakukan pada bulan September 2013 di Taman Nasional Gunung Merapi, Yogyakarta dengan tujuan untuk mengetahui data ekologi Begonia di habitat alaminya serta tumbuhan bawah yang ada di sekitarnya. Pengambilan sampel dilakukan dengan membuat plot ukuran 2 × $2 \mathrm{~m}$ secara purposive sampling. Data lingkungan yang diperoleh masing-masing plot pada habitat Begonia dianalisis menggunakan Canonical Corespondence Analysis (CCA) dengan program Canoco untuk mengetahui seberapa besar pengaruh faktor-faktor ini terhadap keberadaan Begonia. Data kelimpahan (abudance) vegetasi ditabulasikan ke dalam format excel spreadsheet yang diinput ke dalam software PRIMER. Data dilakukan pre-treatment dengan square root transformation kemudian dihitung matriks kemiripan atau resemblance matrix berdasarkan indeks kemiripan Bray-Curtis sebagai dasar analisis Non Metric Multidimensional Scaling ordination/NMDS untuk mengetahui sebaran kelimpahan Begonia. Sebanyak 3 jenis Begonia yang dapat ditemukan di sebagian kawasan Taman Nasional Merapi diantaranya Begonia multangula Blume, B. hirtella Link dan B. tenuifolia Draynd. Begonia hanya dijumpai di Bukit Plawangan dan Bukit Pranajiwa. Tumbuh secara mengelompok pada ketinggian 1004-1164 $\mathrm{m}$ dpl. Tumbuh pada kemiringan lahan 27-40\%, pH tanah 6.6-6.9, kelembaban tanah 10-19\%. Begonia memiliki preferensi asosiasi dengan ketinggian tempat dan kelembaban tanah. Sumbu altitude lebih signifikan berperan dalam distribusi Begonia di lokasi studi dibandingkan sumbu lingkungan kelembaban tanah. Hasil penelitian ini diharapkan dapat memberikan informasi yang bermanfaat dalam melakukan aklimatisasi dan konservasi Begonia.

Kata kunci : Begonia, autekologi, Taman Nasional Gunung Merapi Yogyakarta

\begin{abstract}
The study was conducted in September 2013 at the National Park of Mount Merapi, Yogyakarta in order to determine ecological data Begonia in their natural habitat as well as under the existing plants in the vicinity. Making sampling a plot size of $2 \times 2 \mathrm{~m}$ with purposive sampling. Environmental data obtained each plot on Begonia habitat analyzed using correspondence Canonical Analysis (CCA) with Canoco program to determine how much influence these factors to the existence of Begonia. Data abudance vegetation tabulated excel spreadsheet into a format that is inputted to the PRIMER software. The data pre-treatment with a square root transformation then calculated matrix likeness or resemblance matrix based on Bray-Curtis similarity index as the basis for the analysis of non-metric Multidimensional Scaling ordination/NMDS to determine the distribution of an abundance of Begonia. A total of 3 species of Begonia that can be found in most of the National Park of Merapi including Begonia multangula Blume, B. hirtella Link and B. tenuifolia Draynd. Begonia is only found in Plawangan and Pranajiwa Hill. Grow clumped at an altitude of 1004-1164 m above sea level. Grow at 27-40\% slope, soil pH 6.66.9, soil moisture 10-19\%. Begonias have a preference associated with altitude and soil moisture. Axis altitudes more significant role in the distribution of Begonia in the study area compared to wick soil moisture environment. Result research is expected to provide useful information in conducting acclimatization and conservation Begonia.
\end{abstract}

Keywords: Begonia, autecology, National Park of Mount Merapi Yogyakarta

\section{PENDAHULUAN}

Begonia merupakan salah satu dari enam genus tanaman berbunga terbesar di dunia, sebanyak 10.000 Begonia hybrid bahkan lebih (Tebbitt, 2005) dan lebih dari 1.700 jenis Begonia alam yang dapat dilaporkan.
Keanekaragaman tertinggi ada di Asia Tenggara (Hughes, 2008 dan masih banyak jenis yang dijumpai kemudian). Di Indonesia Begonia alam (Begonia berasal dari alam) diperkirakan berjumlah 213 jenis dan bahkan beberapa jenis Begonia alam akan terungkap kemudian (Undaharta, dkk., 2015). Begonia asal Indonesia tersebar di berbagai 
pulau seperti, Kalimantan, Sulawesi, Sumatra, Jawa, Bali, Nusa Tenggara Timur, Nusa Tenggara Barat, Maluku dan Papua. Keanekaragaman jenis tertinggi ada di pulau Sumatra (Hughes, 2008).

Begonia biasanya tumbuh mengelompok pada tebing hutan, pegunungan, limestone, air terjun, maupun tepi sungai berbatu dan lembab. Begonia tumbuh pada ketinggian 20-1800 m dpl. Jenis Begonia terestrial herba (kadang-kadang epifit) atau undershurbs dan rhizomatous dapat dijumpai pada iklim lembab subtropis dan tropis. Sejak abad 17 banyak jenis Begonia ditemukan di banyak negara seperti Mexico, Amerika Selatan, Amerika Tengah, Afrika dan Asia Selatan (Tebbitt, 2005). Jenis Begonia alam yang dapat dijumpai tumbuh liar di alam biasanya tegak, bertangkai, merayap (creeping) dan berumbi (rhizomatous).Begonia dapat diperbanyak dengan biji, umbi, stek daun dan stek batang. Memahami karakteristik dari setiap individu jenis tumbuhan sangat penting untuk memiliki pengetahuan terkait habitat dari setiap individu jenis (Lawrence, 2002). Jumlah penelitian taksonomi sangat meningkat di Indonesia namun ketika data autekologi dari setiap individu jenis dipertanyakan khususnya autekologi Begonia sangat terbatas literatur yang ada. Penelitian autekologi Begonia masih jarang dilaporkan khususnya autekologi Begonia di Taman Nasional Gunung Merapi sehingga penelitian ini dianggap perlu dilakukan.

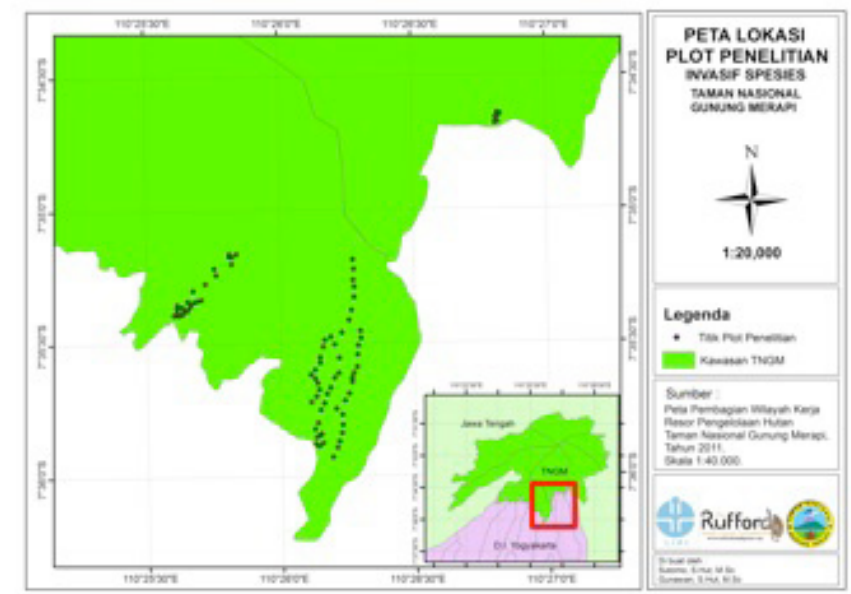

Gambar 1. Peta lokasi sampling di kawasan Taman Nasional Gunung Merapi. Sumber : Peta pembagian wilayah kerja Resor Pengelolaan Hutan Taman Nasional Gunung Merapi Tahun 2011

\section{MATERI DAN METODE}

Penelitian autekologi Begonia dilakukan di sebagian Taman Nasional Gunung Merapi pada bulan September 2013. Lokasi penelitian meliputi Kalikuning (KL), Kaliadem (KD), Bukit Plawangan (PL) dan Bukit Pranajiwa (PR) (Gambar 1). Secara astronomis Taman Nasional berada antara koordinat $07^{\circ} 22^{\prime} 33^{\prime}-07^{\circ} 52^{\prime} 30 \mathrm{LS}$ dan $110^{\circ} 15^{\prime}$ oo' $-110^{\circ} 37^{\prime} 30^{\prime}$ BT. Sedangkan luas totalnya sekitar 6.410 ha, dengan 5.126,01 ha di wilayah Jawa
Tengah dan 1.283,99 ha di Yogyakarta. Kawasan Taman Nasional Gunung Merapi tersebut termasuk wilayah kabupaten Magelang, Boyolali dan Klaten di Jawa Tengah serta Sleman di Yogyakarta.

Pengambilan sampel dilakukan secara purposive sampling dengan melakukan penjelajahan kawasan hutan di sebagian Taman Nasional Gunung Merapi untuk mencari jenis-jenis Begonia setelah dijumpai kemudian membuat plot berukuran $2 \times 2 \mathrm{~m}$. Data yang diambil meliputi jumlah individu Begonia, kondisi vegetasi tumbuhan bawah di sekitarnya serta beberapa faktor lingkungan seperti $\mathrm{pH}$ tanah, kelembaban tanah, ketinggian dan intensitas cahaya (Loewen, dkk.,, 2001 dalam Sutomo dan Mukaromah, 2010; Sutomo dan Fardila, 2013).

Data lingkungan yang diperoleh dari masing-masing plot pada habitat Begonia dianalisis menggunakan Canonical Correspondence Analysis (CCA) dengan program CANOCO untuk mengetahui seberapa besar pengaruh faktor-faktor ini terhadap keberadaan Begonia. Data Data kelimpahan (abundance) vegetasi ditabulasikan ke dalam format excel spreadsheet yang diinput ke dalam software PRIMER (Clarke, 1993; Clarke dan Ainsworth, 1993; Clarke dan Gorley, 2005). Data tersebut kemudian dilakukan pre-treatment dengan square root transformation sebelum kemudian dihitung matriks kemiripan atau resemblance matrix berdasarkan indeks kemiripan Bray-Curtis sebagai dasar analisis Non Metric Multidimensional Scaling Ordination/NMDS untuk mengetahui sebaran kelimpahan Begonia (Clarke, 1993).

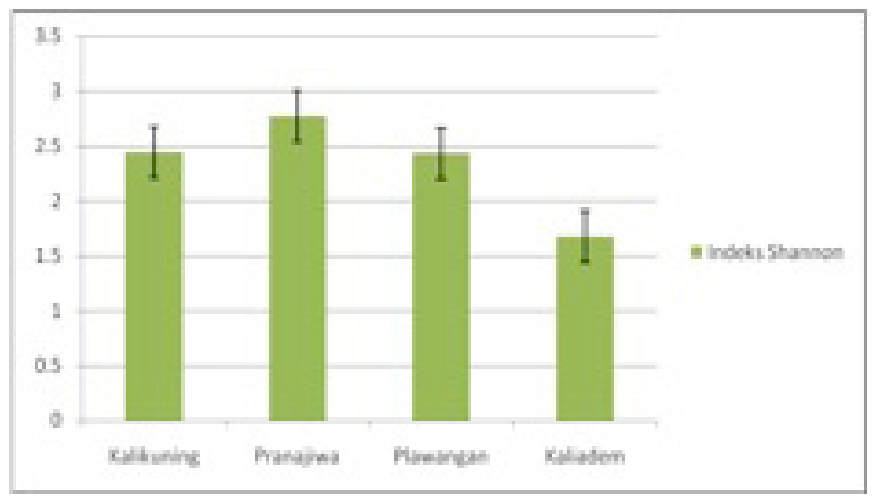

Gambar 2. Indeks keanekaragaman jenis tumbuhan bawah Shannon-Wiener

Sumber : Program PRIMER

\section{HASIL}

\section{Keanekaragaman Jenis Tumbuhan Bawah, Seba- ran Dan Kelimpahan Begonia}

Hasil penelitian menunjukkan sebanyak 134 jenis tumbuhan bawah di lokasi sampling. Keanekaragaman jenis tumbuhan bawah tertinggi ditemukan di sekitar Bukit Pranajiwa (Gambar 2). Sedangkan pohon dominan yang dijumpai di kawasan Plawangan dan Pranajiwa 


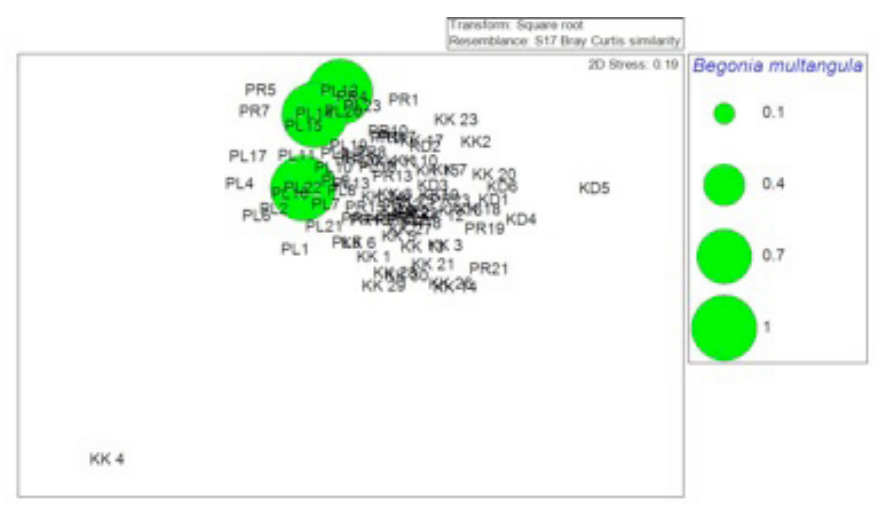

Gambar 3. Sebaran Kelimpahan Begonia di sebagian Taman Nasional Gunung Merapi (Sumber : Program PRIMER)

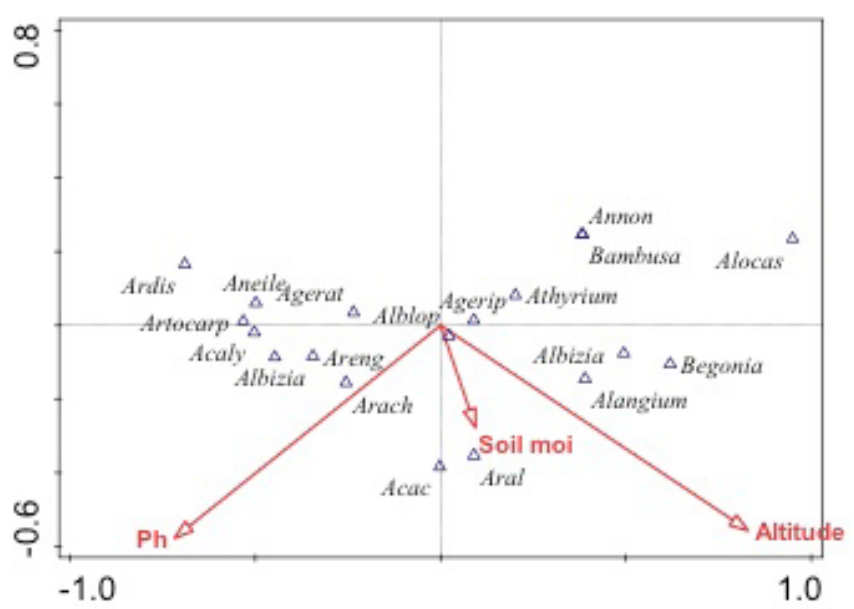

Gambar 4. Pengaruh faktor lingkungan terhadap sebaran Begonia Sumber : Canonical Correspondence Analysis (CCA) data lingkungan dengan menggunakan program CANOCO

adalah Acacia decurrens Willd., Albizia chinensis (Osbeck) Merr., Schima wallichii Choisy dan Trema orientalis (L.) Blume.

\section{Hubungan Distribusi Tumbuhan Bawah dan Be- gonia dengan Faktor Lingkungan}

Hasil Canonical Correspondance Analysis/CCA (Gambar 4) memperlihatkan bahwa sebaran Begonia multangula letaknya lebih dekat dengan sumbu lingkungan ketinggian (altitude) dan kelembaban tanah (soil moist) dibanding dengan sumbu lingkungan $\mathrm{pH}$.

Tabel 1. Sebaran Begonia berdasarkan ketinggian tempat Begonia di sebagian Taman Nasional Gunung Merapi

\begin{tabular}{|c|c|c|c|c|c|}
\hline Jenis & Jumlah & $\begin{array}{l}\text { Keting- } \\
\text { gian tem- } \\
\text { pat } \\
\text { (m dpl.) }\end{array}$ & $\begin{array}{c}\text { Kelem- } \\
\text { baban } \\
(\mathrm{rH})\end{array}$ & $\mathrm{pH}$ tanah & $\begin{array}{l}\text { Kemi- } \\
\text { ringan } \\
\text { lahan }\end{array}$ \\
\hline B. hirtella Link & 50 & 1004 & 60 & 6.6 & 40 \\
\hline $\begin{array}{l}\text { B. tenuifolia } \\
\text { Draynd. }\end{array}$ & 20 & 1071 & 70 & 6.6 & 90 \\
\hline $\begin{array}{l}\text { B. multangula } \\
\text { Blume }\end{array}$ & 7 & $\begin{array}{c}1086- \\
1164\end{array}$ & 60 & 6.9 & 20 \\
\hline
\end{tabular}


jenis tumbuhan bawah serta absennya Begonia di kawasan ini. Sebaliknya gambar 3 memperlihatkan hasil analisis non-metric multidimensional scaling (nmds) berdasarkan kelimpahan jenis B. multangula paling banyak dijumpai di Bukit Plawangan dan Bukit Pranajiwa. Hal ini kemungkinan disebabkan oleh karena sifat Begonia itu sendiri yang pada umumnya lebih "menyukai" tempat-tempat yang relatif lebih lembab serta agak ternaungi. Sebagian besar Begonia tumbuh di hutan hujan tropis, kelerengan yang curam, permukaan batu, ternaungi, terdapat sungai kecil dan air terjun (Kiew, 2005; Phutthai, dkk., 2009; Undaharta, dkk., 2015). Selain itu Begonia tumbuh pada daerah yang memiliki topografi miring, berbatu karst dan menempel pada batu kapur dan biasanya dekat dengan sumber air yang selalu mengalir (Kiew, 1998, 2001a, 2001b; Kiew, 2005; Kiew dan Sang, 2009). Banyak jenis Begonia berasal dari Asia dapat tumbuh dengan baik dengan menempel di batu, tumbuh pada lantai hutan dan Kiew, 2005 menunjukkan bahwa lantai hutan sebagai habitat Begonia dengan kemiringan cenderung curam dimana seresah tidak terkumpul dan drainase yang baik sehingga tidak menghambat pembentukan dan pertumbuhan semai.

\section{Hubungan Distribusi Tumbuhan Bawah dan Be- gonia dengan Faktor Lingkungan}

B. multangula memiliki distribusi yang luas dan dapat dijumpai di Jawa, Sumatera dan Kepulauan Sunda Kecil, B. multangula tumbuh di pegunungan dengan ketinggian 700-2500 m. dpl. (Hughes, 2008; Hughes dan Girmansyah, 2011). Di Bali B. multangula dapat dijumpai di beberapa kawasan hutan seperti Bukit Sengayang (Kabupaten Buleleng), Bukit Tapak (Kabupaten Tabanan), Bukit Sang Hyang (Kabupaten Tabanan), Desa Plaga (Kabupaten Badung), Desa Manikliyu (Kabupaten Bangli), Bukit Abang (Kabupaten Karangasem) dan Kabupaten Jembrana (Undaharta dkk., 2013). Hasil analisis CCA menunjukkan bahwa jenis Begonia yang dijumpai di lokasi studi, lebih berkorelasi positif terhadap sumbu altitude dan soil moisture. B. multangula dijumpai pada ketinggian 1086$1164 \mathrm{~m}$ dpl. serta kelembaban tanah 6o. B. multangula yang dijumpai di Plawangan tersebar di beberapa plot pengamatan dan keberadaan $B$. multangula dipengaruhi oleh ketinggian tempat (altitude) dan kelembaban tanah (soil moist) (gambar 4). Hal ini dapat diartikan bahwa kemungkinan besar jenis ini memiliki preferensi asosiasi dengan ketinggian tempat dan kelembaban tanah sebagai habitatnya di Bukit Plawangan kawasan Taman Nasional Gunung Merapi. Analisis ini juga mengungkap, bahwa sumbu altitude lebih signifikan berperan dalam distribusi Begonia di lokasi studi dibandingkan sumbu lingkungan kelembaban tanah. Begonia juga kerap dijumpai hidup bersama dengan beberapa jenis tumbuhan bawah lainnya seperti Alangium sp., dan Albizia sp. pada sumbu lingkungan ketinggian (altitude). Begonia pada lokasi studi dijumpai pada rentang altitude mulai 1004-1164 m dpl. Sedangkan untuk rentang $\mathrm{pH}$ Begonia di lokasi studi dijumpai pada rentang 6,6-6,9. Tidak hanya $B$. multangula yang dipengaruhi oleh ketinggian tempat dan kelembaban tanah namun $B$. tenuifolia dan $B$. hirtella juga memiliki habitat yang hampir sama. Begonia yang dijumpai di Taman Nasional Gunung Merapi mampu tumbuh pada ketinggian tempat dengan kisaran 1004$1164 \mathrm{~m}$ dpl. sedangkan kelembaban tanah berada pada kisaran 60-70 (Tabel 1).

\section{Karakteristik Begonia yang Dijumpai pada Ka- wasan Bukit Plawangan Merapi}

Begonia yang dapat ditemukan di sebagian Taman Nasional Gunung merapi tumbuh secara mengelompok dan jumlah individu yang sangat sedikit. Meskipun demikian pertumbuhan dari Begonia tersebut sangat baik. Sebanyak tiga jenis Begonia yang dapat dijumpai di sebagian Taman Nasional Gunung Merapi diantaranya Begonia hirtella Link, B. tenuifolia Draynd. dan $B$. multangula Blume.

Begonia tenuifolia salah satu jenis yang menarik untuk diamati mengingat jenis ini memiliki varietas yang sangat banyak. B. tenuifolia pertama kali ditemukan oleh seorang ahli taksonomi bernama Jonas Carlsson Drander tahun 1791. B. tenuifolia di Taman Nasional. Gunung Merapi memiliki perbedaan pada daun jika dibandingkan dengan B. tenuifolia di Air terjun Gitgit, Buleleng, Bali. B. tenuifollia Taman Nasional Gunung Merapi tidak memiliki bercak-bercak putih pada permukaan atas daun dan memiliki pertulangan daun yang jelas berwarna merah sedangkan $B$. tenuifolia di Air Terjun Gitgit Buleleng, Bali memiliki bercak-bercak berwarna putih. Berumbi 1-2 cm, merayap (membentuk rhizome), ukuran daun kecil 3-5 cm, berbentuk bulat dan ujungnya runcing. Warna daun hijau dengan tulang daun berwarna merah. Banyak faktor yang menyebabkan terjadinya perbedaan dari B. tenuifolia di Taman Nasional Gunung Merapi dengan di air terjun Gitgit. Faktor penyebab terjadinya perbedaan jenis tersebut seperti intesitas cahaya, suhu dan kadar air. Pengaruh unsur cahaya pada tanaman tertuju pada pertumbuhan generatif. Tanggapan tanaman terhadap cahaya ditentukan oleh sintesis hijau daun, kegiatan stomata (respirasi, transpirasi), pembentukan anthosianin, suhu dari organ-organ permukaan, absorpsi mineral hara, permeabilitas, laju pernafasan dan aliran protoplasma (Jumin, 2008), dengan demikian semakin besar jumlah energi yang tersedia akan memperbesar jumlah hasil fotosintesis.Siklus hidup $B$. tenuifolia pendek, sekitar 3 bulan. Setelah mencapai fase generatif, tumbuhan akan layu, kering, kemudian mati. Namun umbinya masih dapat tumbuh kembali. B. tenuifolia berbunga banyak pada bulan Januari-April. Pada bulan Desember bunga akan muncul kembali namun sedikit. Distribusi: Jawa, Sumatra, Bali, Nusa Tenggara. Habitat: tumbuh di tempat teduh/terlindung, selokan berbatu curam dan kadang-kadang tumbuh di batu berkapur, 


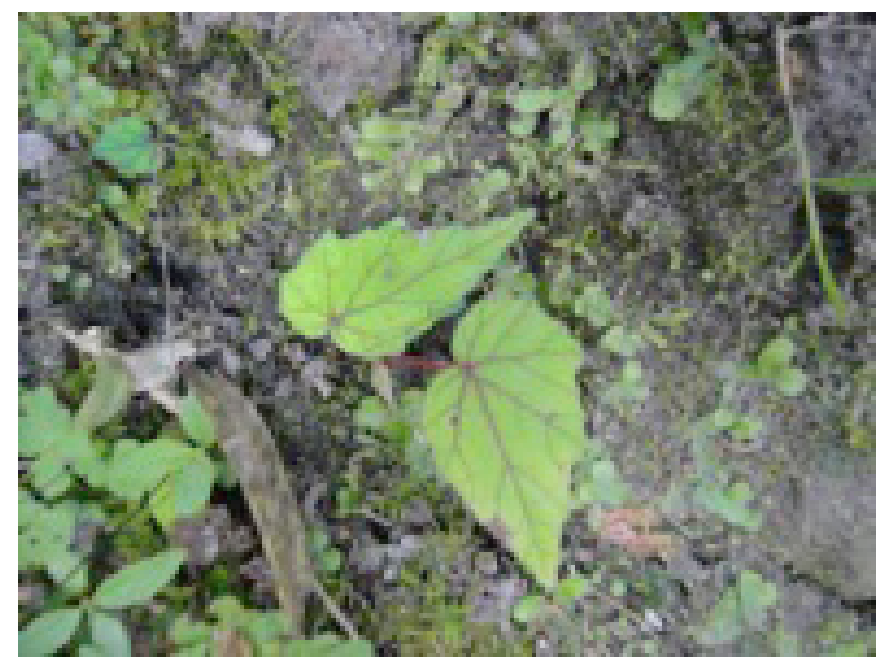

Gambar 5. Begonia tenuifolia Dryand.

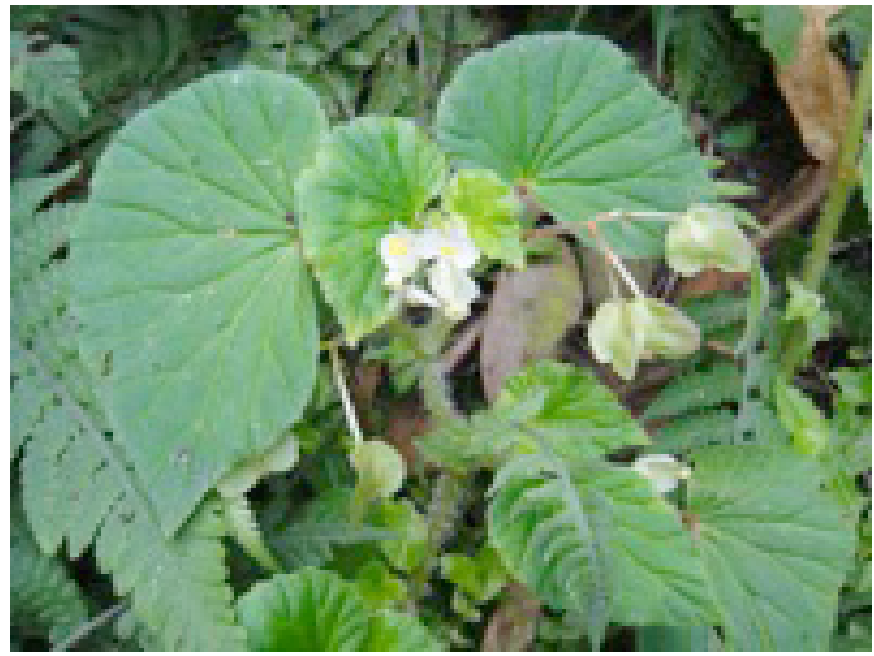

Gambar 6. Begonia hirtella Link

\section{0-900 m dpl.}

Begonia hirtella termasuk native species Brazil, umumnya menggulma di tempat lembab dan ternaungi di daerah pegunungan, tumbuh di ketinggian $918 \mathrm{~m}$ dpl. kemiringan $90^{\circ}$. Tebbit (2005) menyebutkan B. hirtella yang berasal dari India Barat hingga Amerika dan tumbuh pada areal terganggu. Di Plawangan $B$. hirtella dijumpai menempel pada tanah berbatu, tumbuh mengelompok dan tidak terlalu basah. $B$. hirtella termasuk terna tegak dengan ukuran tidak terlalu besar, tinggi 20-30 $\mathrm{cm}$. Batangnya memiliki ruas dengan panjang setiap ruas sekitar 5,5 cm. Daunnya kecil dan memiliki bulu berwarna putih dan lembut. Bunga $B$. hirtella berwarna putih dan berukuran kecil. Begonia hirtella mudah diperbanyak dengan biji.

Begonia multangula termasuk Begonia yang paling sering dijumpai di Taman Nasional Gunung Merapi, tumbuh di tanah dengan sedikit seresah, topografi sedikit miring, ternaungi, jenis ini tumbuh pada ketinggian 914 - $1169 \mathrm{~m}$ dpl. B. multangula atau biasa disebut bacem (tumbuhan berbatang basah dan tidak berkayu atau hanya mengandung sedikit jaringan kayu) yang tumbuh dengan tinggi 1 - 1,5 meter. Daun berbentuk lebar dengan

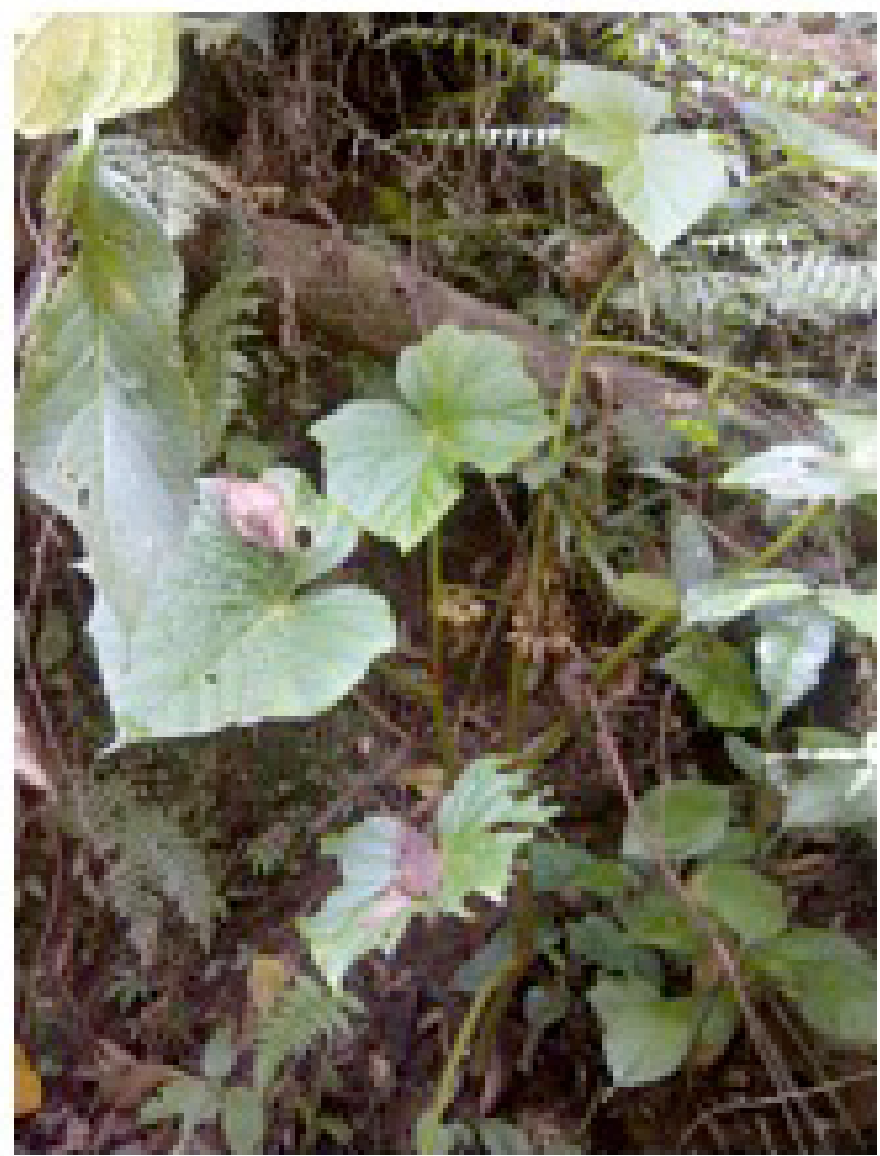

Gambar 7. Begonia multangula Blume

diameter $20-25 \mathrm{~cm}$. Daun B. multangula yang masih muda bisa dimakan.

Penelitian ekologi Begonia perlu dilakukan agar dapat memperoleh hasil maksimal terutama dalam hal teknik budidaya dengan menyesuaikan karakteristik lingkungan alami dari jenis Begonia yang akan ditanam, sehingga dapat memperbesar potensi keberhasilan tumbuh. Pembelajaran ekologi Begonia membuat pemahaman teknik dan cara yang tepat dan cermat dalam mengambil manfaat terbaik dari jenis Begonia tanpa harus merusaknya.

\section{SIMPULAN}

Sebanyak tiga jenis Begonia dijumpai di sebagian kawasan Taman Nasional Gunung Merapi (B. hirtella, $B$. tenuifolia, B. multangula). Begonia di Taman Nasional Gunung Merapi kerap dijumpai hidup bersama dengan beberapa jenis tumbuhan bawah lainnya seperti Alangium sp., dan Albizia sp. Begonia di Taman Nasional Gunung Merapi mampu tumbuh dengan kisaran 1004-1164 m dpl. sedangkan kelembaban tanah berada pada kisaran 60-70. Begonia memiliki preferensi asosiasi dengan ketinggian tempat dan kelembaban tanah. Bukit Plawangan dan Pranajiwa termasuk lokasi yang paling baik sebagai tempat tumbuh Begonia. 


\section{UCAPAN TERIMA KASIH}

Terima kasih kepada rekan teknisi Kebun Raya Bali I Ketut Sandi, serta Gunawan PEH dari Taman Nasional Gunung Merapi atas bantuannya dalam kegiatan ini. Penelitian ini didukung oleh Rufford Foundation for Conservation, 2013 (RUFFORD ID 13139-2. SUTOMO)

\section{KEPUSTAKAAN}

Clarke. K.R. 1993. Non parametric multivariate analyses of changes in community structure. Aust. J. Ecol. 18:117-143.

Clarke. R.K. and M. Ainsworth. 1993. A method of linking multivariate community structure to environmental variables. Marine Ecology Progress Series 92: 205-219.

Clarke. R.K., R.N. Gorley. 2005 PRIMER: Plymouth Routines In Multivariate Ecological Research PRIMER-E Ltd., Plymouth. Hughes, M. 2008. An annotated checklist of southeaast asian Begonia. Edinburgh : Royal Botanic Garden Edinburgh, UK.

Indriyanto, 2006. Ekologi Hutan. Penerbit Bumi Aksara. Jakarta.

Hughes, M. dan Deden Girmansyah, 2011. A revision of Begonia sect. Sphenanthera (Hassk.) Warb. from Sumatra. Garden's Bulletin Singapore 62(2):27-39.

Kiew, R. 1998. Niche partitioning in limestone Begonias in Sabah, Borneo, including two new species. Gardens' Bulletin Singapore 50:161-169.

Kiew, R. 2001. The limestone Begonias of Sabah, Borneo: Flagship species for conservation. Gardens' Bullletin Singapore 53:241-286.

Kiew, R. 2001b. Towards a limestone flora of Sabah. Malayan Nature Journal. 55:77-93.

Kiew, R. 2005. Begonias of peninsular Malaysia natural history publications (Borneo), Kota Kinabalu.

Kiew, R. dan Sang, 2009. Seven new species of Begonia (Begoniaceae) from the Ulu Merirai and Bukit Sarang limestone area in Sarawak, Borneo. Gardens' Bulletin Singapore 60:351-372.
Lawrence, M.J. 2002. A comprehensive collection and regeneration strategy for ex situ conservation. Genetic Resources and Crop Evolution 49:199-209.

Loewen, D.C., G.A. Allen, J.E. Antos. 2001. Autecology of Erythronium grandiflorum in Western Canada Can J. Bot. 9:500 dalam Sutomo dan Laily Mukaromah. 2010. Autekologi purnajiwa (Euchresta Horsfieldii (Lesch.) Benn. (Fabaceae) di sebagian kawasan hutan Bukit Tapak Cagar Alam Batukahu Bali. J. Biol. XIV(1):24-28.

Phutthai, T., Sands, M. dan Siridith, K. 2009. Field surveys of natural populations of Begonia L. in Thailand. Thai Forest Bulletin (Botany). Special Issue: 186-196.Sutomo dan Mukaromah, L. 2010. Autekologi Purnajiwa (Euchresta horsfieldii (Lesch.) Benn. (Fabaceae) di sebagian kawasan hutan Bukit Tapak Cagar Alam Batukahu Bali. Jurnal Biologi XIV(1):24-28.

Sutomo, Hobbs R.J. and Cramer V.A. 2011. Plant community establishment on the volcanic deposit following nuees ardentes of Mount Merapi : diversity and floristic variation. J. Biodiversitas 12:86-91.

Sutomo, Fardilla, D., 2012. Plant community and soil relationship following wildfires from nuees ardentes of Mount Merapi Indonesia. Biotropia 19.

Sutomo and Fardilla D. 2013. Autecology of traditional medicine plant of Selaginella doederleinii hieron in some areas of Mount Pohen Forest Batukahu Nature Reserve Bedugul, Bali. J. Penelitian Hutan dan Konservasi Alam 10:153-161.

Tebbitt. M.C. 2005. BEGONIAS Cultivation, Identification and Natural History. Timber Press, Inc. USA

Undaharta, N.K.E., IM. Ardaka dan Hartutiningsih M. Siregar, 2013. Tiga seksi Begonia dari pulau Bali. Prosiding Simposium, Workshop dan Kongres IX PTTI. Organisasi Profesi Pendorong Percepatan Perkembangan IPTEK. Bali, 11-13 Oktober 2011. LIPI Press. Jakarta..

Undaharta, NKE., Ardaka, IM., Agung Kurniawan, Bayu Adjie. 2015. Begonia bimaensis, a new species of Begonia from Sumbawa Island, Indonesia. Garden's Bulletin Singapore 67 (1):95-99. doi: 10.3850/S2382581215000101 